\title{
Overcoming nutrient loss during volatile fatty acid recovery from fermentation media by addition of electrodialysis to a polytetrafluoroethylene membrane stack
}

\author{
Rhiannon Chalmers Brown, Romain Tuffou, Jaime Massanet Nicolau*, Richard Dinsdale, \\ Alan Guwy \\ University of South Wales, Glyntaff, Pontypridd, Rhondda Cynon Taff CF37 4BD, UK
}

\section{G R A P H I C A L A B S T R A C T}

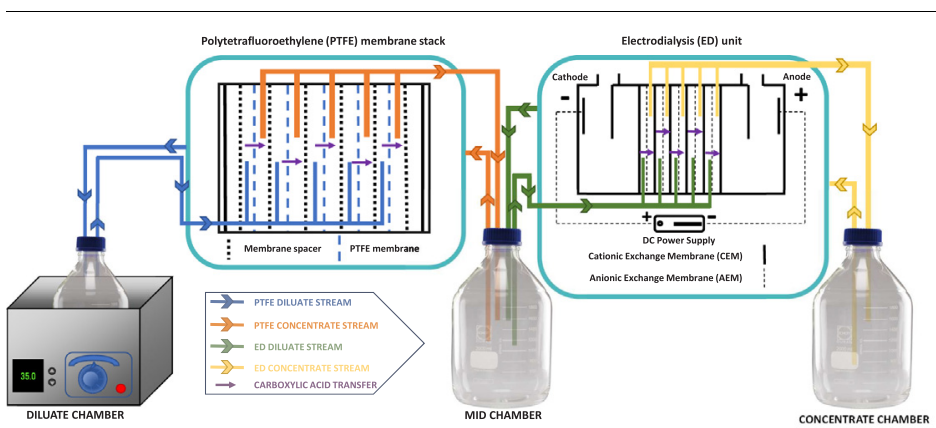

\section{A R T I C L E I N F O}

\section{Keywords:}

PTFE

Electrodialysis

Volatile fatty acids

Extraction

Fermentation media

\begin{abstract}
A B S T R A C T
This research investigated the use of an innovative polytetrafluoroethylene (PTFE) membrane configuration coupled to electrodialysis for the in-situ removal of Volatile Fatty Acids (VFAs) from a mixed culture bioreactor. It was shown that by stacking the PTFE membranes to increase the active membrane surface area, shortened VFA recovery times was seen. The addition of electrodialysis to the PTFE membrane stack enabled the continuous extraction of VFAs from fermentation media whilst retaining essential nutrients and organic compounds in the diluate stream. Ammonium, phosphate and nitrate remained in the diluate chamber and did not cross the PTFE membrane stack. Up to $98 \%$ of total VFA recovery was achieved with the PTFE and electrodialysis system. The process was shown to extract from a reservoir of low VFA concentration to a reservoir with a VFA concentration 10 times higher. These results show that the addition of electrodialysis to PTFE provides a robust solution for the in-situ extraction of VFAs from fermentation media within bioreactors to support the demand for sustainable fuels and green chemical feedstocks.
\end{abstract}

\section{Introduction}

In recent years, research has been directed at developing processes for converting commercial and industrial waste streams to a variety of green commodity chemicals and products (Daniell et al., 2012; Jones et al., 2017). Carbon rich syngas and industrial off-gas streams have been used to produce acids, alcohols and lipids (Daniell et al., 2012; Nam et al., 2016) whilst biomass has been proven as a sustainable route

\footnotetext{
* Corresponding author.

E-mail address: jaime.massanet@southwales.ac.uk (J. Massanet Nicolau).
} 
for renewable hydrogen production and volatile fatty acid (VFA) production (Massanet-Nicolau et al., 2015).

Acetogens naturally metabolise carbon monoxide, carbon dioxide and hydrogen under anaerobic conditions to produce acetic acid and other VFAs. Anaerobic gas fermentation is widely recognised as a viable solution to the clean-up of industrial greenhouse gases (GHGs) and the production of sustainable commodity chemicals, and has been demonstrated commercially by several companies (Daniell et al., 2012; Köpke et al., 2011). Acetic acid has been described as one of the world's most important chemicals (Kersten et al., 2014). It is a useful building block for biopolymers, plastics and compounds with the current market revenue at approximately $\$ 12$ billion. The commercial production of acetic acid via biofermentation has previously been neglected in favour of ethanol production due to the challenges of extracting acetic acid from fermentation media. Separation of VFAs from effluent streams is typically challenging due to their polarity, low concentrations and mineral rich media (Atasoy et al., 2018; Reyhanitash et al., 2017). Extensive research has been carried out in the recovery of organic acids from fermentation media using a wide variety of techniques (Alkaya et al., 2009; Reyhanitash et al., 2017; Zacharof and Lovitt, 2014). These include, but are not limited to, Reverse Osmosis (RO), commonly used to remove salt and other effluent materials from seawater and brackish water for preparation as drinking water, Liquid-Liquid Extraction (LLE), Adsorption and Electrodialysis. Volatile products such as ethanol are recovered using distillation methods already well established at industrial scale, although the energy requirements for distillation are much higher when compared to other methods.

Electrodialysis is a process whereby the movement of ions is aided by an applied electric field across the semipermeable cationic and anionic membranes. Electrodialysis is mainly used for the desalination of water but has also been used for the removal of nitrates from drinking water (Kesore et al., 1997), phosphate recovery from sludge (Wang et al., 2013) and ammonium sulphate recovery from fermentation waste (Lee et al., 2003). Electrodialysis has been used to manipulate the end products of anaerobic digestion and optimise the yield of products formed (Jones et al., 2015), however, the use of electrodialysis to extract VFAs poses some challenges when attached directly to a bioreactor. Electrodialysis is not selective to VFAs alone, leading to loss of nutrients from the fermentation broth and therefore lowered rates of bacterial growth and acetic acid production respectively. This could compromise the fermentation, and lead to a less pure VFA product. The use of electrodialysis alone for producing a concentrated acid is not promising unless salt levels can be reduced and acid levels increased in the medium (Weier et al., 1992).

Polytetrafluoroethylene (PTFE) membranes have been reported as a possible cost effective and robust solution to the extraction of VFAs from complex matrices (Aydin et al., 2018). PTFE is hydrophobic, has excellent chemical resistance and is produced industrially for a wide range of applications. PTFE membranes allow volatile compounds to pass through the pores whilst the hydrophobicity prevents water molecules from crossing, along with any water soluble, non-volatile molecules and ions, therefore enabling the separation of VFAs from solution (Fig. 1) without the co-extraction of other non-desirable components.

PTFE membrane vapour permeation relies on passive transport of molecules across the membranes and depends on the tendency of the system to grow in entropy. A concentration gradient must be maintained to continuously extract from the diluate stream to prevent the system from reaching equilibrium. PTFE membranes are conventionally used in conjunction with a base at the concentrate side to neutralise the acid and maintain the concentration gradient (Aydin et al., 2018). This adds chemical cost to the process, as well as producing the carboxylic acid salt instead of the protonated carboxylic acid. It was hypothesised that PTFE and electrodialysis could be used in line to remove VFAs from mesophilic anaerobic fermentation media without removing essential nutrients, transferring molecules or ions that could reduce electrodialysis membrane efficiency and eliminating the requirement for additional chemicals. If successful, this would result in a more widely desirable product for market and enable continued production of the acids within a bioreactor.

This research investigated an innovative membrane configuration for the in-situ removal of VFAs from a mixed culture bioreactor. The aim was to investigate whether a PTFE membrane stack can separate VFAs from fermentation media without adversely affecting the reactor system. The study compared a single PTFE membrane and a stack of PTFE membranes to increase active membrane surface area and evaluated the addition of electrodialysis to maintain a concentration gradient across the PTFE membrane stack. The effect on nutrients and membrane fouling via silicon antifoam were also studied. If PTFE membrane vapour permeation was found to be capable of the selective removal of VFAs from model solutions and synthetic fermentation media, there is scope for further investigation into the removal of VFAs directly from working bioreactors.

\section{Materials and methods}

\subsection{PTFE membrane module}

A PTFE membrane module constructed from two metal plates and held using rubber coated stainless steel bolts was built. Hydrophobic PTFE membrane with a pore size of $0.45 \mu \mathrm{m}$ and Polypropylene (PP) support layer from Membrane Solutions LLC (USA) was used. The membranes were cut to size using a die cutter with $144 \mathrm{~cm}^{2}$ template and the edges sealed with a commercially available non-toxic silicon sealant to give an active membrane surface area of $64 \mathrm{~cm}^{2}$.

\subsection{Experimental design}

\subsubsection{Phase 1. Stacking of multiple PTFE membranes}

Experiments were carried out with a 1, 3 and 5-membrane configuration with total active membrane surface area of $64 \mathrm{~cm}^{2}, 192 \mathrm{~cm}^{2}$ and $320 \mathrm{~cm}^{2}$ respectively to determine whether the increase in active membrane surface area led to a decrease in VFA recovery times. A $500 \mathrm{~mL}$ aliquot of synthetic feed solution of $1000 \mathrm{mgL}^{-1}$ acetic acid at pH $5.0 \pm 0.1$ was used as the PTFE diluate (PTFE DIL). The temperature of the PTFE DIL was maintained at $35{ }^{\circ} \mathrm{C}$ throughout the duration of the experiment using a water bath to model the temperature conditions of a standard anaerobic fermentation bioreactor (Metcalf \& Eddy Inc, Tchobanoglous and Burton, 1991). A $500 \mathrm{~mL}$ aliquot of deionised water was used for the PTFE concentrate (PTFE CONC). $2 \mathrm{~mL}$ samples were taken from PTFE DIL and PTFE CONC at $t_{0}$ and every $10 \mathrm{~min}$ thereafter for $300 \mathrm{~min}$. Titration using a $5 \mathrm{~mL}$ sample from PTFE CONC against $0.5 \mathrm{M} \mathrm{NaOH}$ was carried out hourly to monitor acetic acid recovery. The 5 membrane experiment was repeated with a $1000 \mathrm{~mL}$ aliquot of synthetic feed solution of $1000 \mathrm{mgL}^{-1}$ acetic acid at pH $5.0 \pm 0.1$ as the PTFE DIL and a $1000 \mathrm{~mL}$ aliquot of deionised water for PTFE CONC. All samples were analysed in triplicate using Headspace Gas Chromatography (HSGC).

\subsubsection{Phase 2. Addition of electrodialysis to maintain a concentration} gradient across the PTFE membrane stack

Experiments were carried out with a 5 membrane configuration, $1000 \mathrm{~mL}$ PTFE DIL and $1000 \mathrm{~mL}$ PTFE CONC to obtain maximum flux, as demonstrated in phase 1. A conventional electrodialysis unit was installed after the PTFE membrane stack to maintain a concentration gradient across the PTFE membranes. The electrodialysis unit was manufactured by PCCell GmbH (Heusweiler, Germany), model ED64002, containing 10 cell pairs with $1280 \mathrm{~cm}^{2}$ active membrane area, with an applied voltage of $18 \mathrm{~V}$. Sodium sulphate solution $(1 \mathrm{M})$ was used as the electrolyte for the electrodialysis. A $1000 \mathrm{~mL}$ aliquot of deionised water was used for the electrodialysis concentrate (ED CONC). Samples were taken and analysed as in phase 1 and for each 


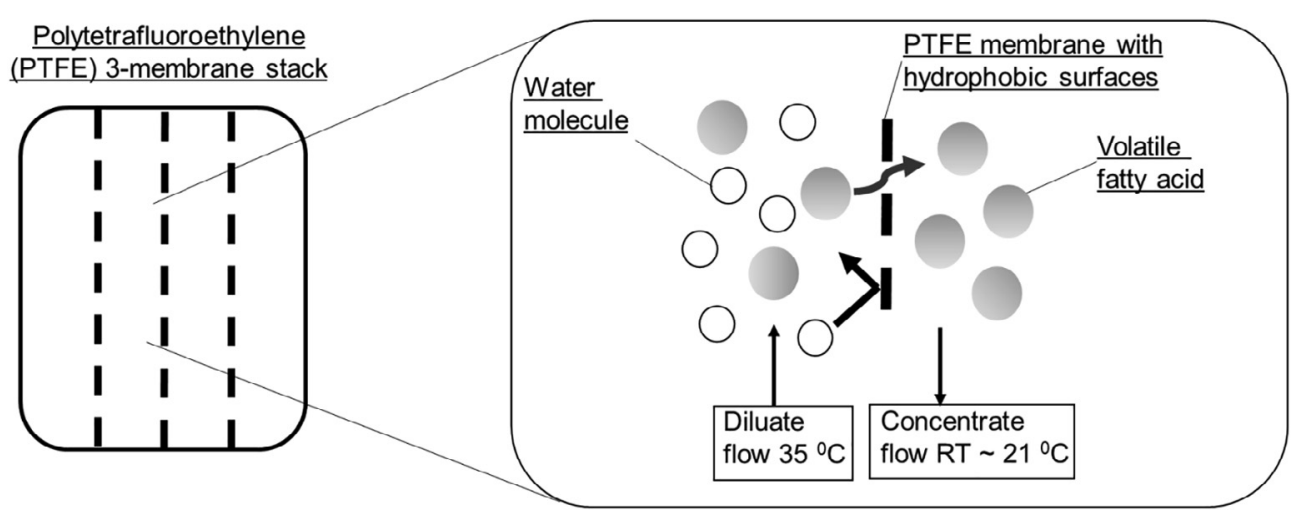

Fig. 1. Schematic of a PTFE membrane stack used to separate VFA molecules from aqueous solution. The diluate flow is maintained at $35{ }^{\circ} \mathrm{C}$ whilst the concentrate flow is maintained at room temperature (RT). The VFAs cross the PTFE membrane whilst the water molecules remain on the diluate side, separating the volatile compounds from the diluate solution. experiment hereafter unless otherwise specified.

The ability of the PTFE/electrodialysis system to extract VFAs against the concentration gradient was tested using the 5-membrane configuration. $1000 \mathrm{~mL}$ of a $5000 \mathrm{mgL}^{-1}$ acetic acid stock solution at pH $5.0 \pm 0.1$ was used as the PTFE DIL, $1000 \mathrm{~mL}$ aliquot of de-ionised water for PTFE CONC and $1000 \mathrm{~mL}$ aliquot of a $50,000 \mathrm{mgL}^{-1}$ acetic acid stock solution $(\mathrm{pH} 3.0 \pm 0.1)$ was used as the ED CONC. Samples of $10 \mathrm{~mL}$ were taken at $\mathrm{t}_{0}$ and $\mathrm{t}_{24}$ hours and analysed in triplicate using HSGC.

\subsubsection{Phase 3. Mixed VFA extraction}

The experiment was set up as in phase 2 using a $1000 \mathrm{~mL}$ synthetic stock solution containing $1000 \mathrm{mgL}^{-1}$ acetic acid, $1000 \mathrm{mgL}^{-1}$ propionic acid, $1000 \mathrm{mgL}^{-1}$ i-butyric acid, $1000 \mathrm{mgL}^{-1} \mathrm{n}$-butyric acid and $1000 \mathrm{mgL}^{-1}$ valeric acid (total start VFA concentration $5000 \mathrm{mgL}^{-1}$ ) as the PTFE DIL to investigate the outcome of a mixed short chain VFA solution.

\subsubsection{Phase 4. Retention of nutrients by the PTFE membrane stack}

The experiment was set up as in phase 2. A nutrient stock solution containing $450 \mathrm{mgL}^{-1}$ potassium phosphate, $1000 \mathrm{mgL}^{-1}$ sodium nitrate, $1000 \mathrm{mgL}^{-1}$ ammonium chloride and $3.6 \mathrm{mgL}^{-1}$ zinc sulphate (Demler and Weuster-Botz, 2011) at pH $5.0 \pm 0.1$ was prepared gravimetrically and diluted in de-ionised water using volumetric glassware. The stock solution was added to the PTFE DIL chamber and samples taken at $t_{0}$ and $t_{24}$ from PTFE DIL, PTFE CONC and ED CONC. Ion chromatography analysis was performed in triplicate by Alliance Technical Ltd, UK, to determine initial and final nutrient concentration.

\subsubsection{Phase 5. Synthetic reactor contents and effect of silicone antifoam}

A $1000 \mathrm{~mL}$ aliquot of synthetic reactor media was prepared to investigate the extraction of acetic acid from synthetic reactor contents. Inoculum from an anaerobic municipal wastewater treatment plant was sieved through a $75 \mu \mathrm{m}$ sieve and diluted $5 \% \mathrm{v} / \mathrm{v}$ in $1 \mathrm{~L}$ deionised water. $1000 \mathrm{mgL}^{-1}$ acetic acid, $450 \mathrm{mgL}^{-1}$ potassium phosphate, $1000 \mathrm{mgL}^{-1}$ sodium nitrate, $1000 \mathrm{mgL}^{-1}$ ammonium chloride and $3.6 \mathrm{mgL}^{-1}$ zinc sulphate were added. The media was then passed through a $0.1 \mu \mathrm{m}$ crossflow filter and added to the PTFE DIL chamber. A $1000 \mathrm{~mL}$ volume of deionised water was used both for the PTFE CONC and the ED CONC. $6 \mathrm{~mL}$ samples were taken from PTFE DIL, PTFE CONC and ED CONC at $t_{0}$ and every 10 min thereafter for $240 \mathrm{~min}$. Samples were analysed in triplicate using HSGC.

The effects of silicone antifoam on the PTFE membranes was investigated using a $1000 \mathrm{mgL}^{-1}$ acetic acid solution with $0.17 \%(\mathrm{v} / \mathrm{v})$ silicone antifoam as the PTFE DIL, and $1000 \mathrm{~mL}$ aliquots of deionised water for PTFE CONC and ED CONC.

\subsection{Analysis and calculations}

Samples were analysed in triplicate via headspace gas chromatography fitted with a free fatty acid phase (FFAP) column and flame ionisation detector (FID) using the method developed in Cruwys et al., 2002. The limit of detection of the HSGC analysis was $50 \mathrm{mgL}^{-1}$.

Flux, defined as the permeate flow of VFA per total membrane surface area, was calculated using the following equation.

$J=\frac{Q}{A}$

where: $J$ is the flux $\left(\mathrm{mgL}^{-1} \mathrm{~h}^{-1} \mathrm{~cm}^{-2}\right), Q$ is the permeate VFA flow $\left(\mathrm{mgL}^{-1} \mathrm{~h}^{-1}\right)$ and $\mathrm{A}$ the surface area of system $\left(\mathrm{cm}^{2}\right)$.

\section{Results and discussion}

\subsection{Extraction of acetic acid across stacked PTFE membranes}

The characteristics of the PTFE membranes used in this work were chosen based on a previous study comparing the characteristics of commercially available membranes for membrane distillation applications (Adnan et al., 2012). It has previously been reported that stacking ultrafiltration membranes during peptide fractionation led to an increase in membrane system performance (Poulin et al., 2007). Developing new membranes and optimising their properties for specific application is relevant yet may not be essential. Membrane stacking could enable the application of existing membranes to processes without the need for resource intensive development. The extraction of acetic acid with 1 membrane and the stacking of multiple PTFE membranes was compared to determine whether the increase in active membrane surface area led to a decrease in acetic acid recovery times. Fig. 2a shows the extraction of acetic acid over time for the 1, 3 and 5 membrane configurations.

Over $4 \mathrm{~h}$, the 1,3 and 5 membrane systems extracted $202 \mathrm{mgL}^{-1}$, $322 \mathrm{mgL}^{-1}$ and $510 \mathrm{mgL}^{-1}$ respectively, from $500 \mathrm{~mL}$ PTFE DIL into $500 \mathrm{~mL}$ PTFE CONC aliquots. This demonstrates that stacking the PTFE membranes enables a larger concentration of acetic acid to be recovered, over the same time period. The flux (J) was calculated over $4 \mathrm{~h}$ for 1,3 and 5 membranes as shown in Fig. 2 b. It was observed that the flux $(J)$ decreased as membrane surface area increased, although the total amount of acetic acid extracted in $4 \mathrm{~h}$ increased with the increase in membrane surface area. The extraction of a $1000 \mathrm{mgL}^{-1}$ acetic acid stock solution from $1000 \mathrm{~mL}$ PTFE DIL into $1000 \mathrm{~mL}$ PTFE CONC was also studied. The system extracted $681 \mathrm{mgL}^{-1}$ in $2 \mathrm{~h}$ with a flux of $1.25 \mathrm{mgL}^{-1} \mathrm{~h}^{-1} \mathrm{~cm}^{-2}$, before reaching a dynamic equilibrium. It appears that increasing the volume of the diluate and concentrate chambers reduces the time it takes to extract the same concentration of acetic acid when using the 5 membrane system. One possible theory is that when using larger volumes, the change in the concentration gradient is slower than when using smaller volumes. The concentration gradient must be maintained to continuously extract from the diluate stream. This prevents the system from reaching equilibrium as PTFE membrane vapour permeation relies on passive transport of molecules 
(a)
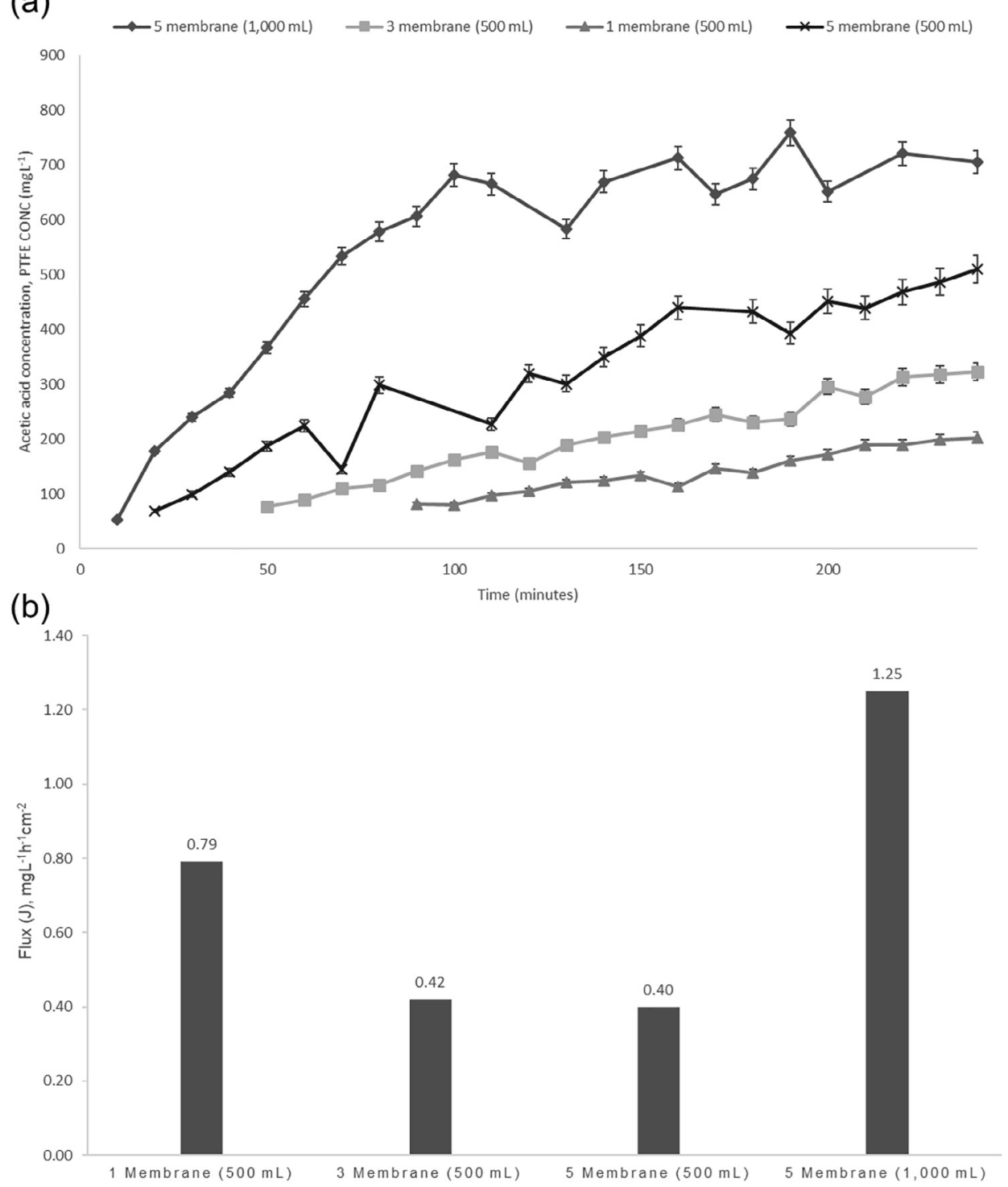

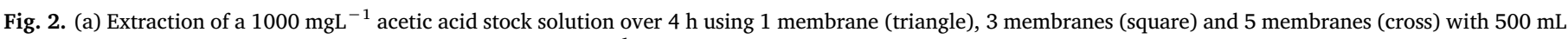

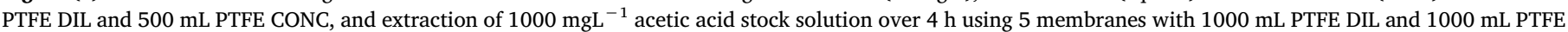

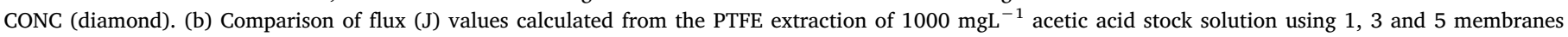
(500 mL PTFE DIL and $500 \mathrm{~mL}$ PTFE CONC) and 5 membranes (1000 mL PTFE DIL and $1000 \mathrm{~mL}$ PTFE CONC).

across the membranes and depends on the tendency of the system to grow in entropy. The slower change in concentration gradient leads to the same amount of acetic acid being extracted in less time. Industrially when working with large reactor volumes this could be of benefit when applying the extraction system, although this may limit the ability of the system using solely PTFE extraction to produce a concentrated solution of VFAs. The 5 membrane extraction using $1000 \mathrm{~mL}$ PTFE DIL and $1000 \mathrm{~mL}$ PTFE CONC demonstrated that a concentration gradient must be maintained for the extraction to be sustained. There are several system variables that could affect the point at which the equilibrium is reached, including the temperature and the $\mathrm{pH}$ of the diluate. The temperature of the PTFE DIL could be increased, raising the energy of the system and shifting the equilibrium, although would not allow the system to concentrate VFAs past the point of equilibrium. In all experiments the initial diluate $\mathrm{pH}$ was $5.0 \pm 0.1$. pH 5.0 is a typical operating $\mathrm{pH}$ for anaerobic acetogenic bioreactors and has been shown to prevent methanogenesis, therefore enhancing acetic acid production (Oh and Logan, 2003; Yu et al., 1998). At low pH values the volatility of acetic acid and other VFAs would increase due to more of the molecules being protonated, possibly leading to a higher VFA flux. It was decided that reducing $\mathrm{pH}$ would not be a viable method to increase VFA flux for this application due to the possible reduction in bacterial activity a lower reactor $\mathrm{pH}$ would cause, leading to lower VFA production. Maintaining the PTFE DIL at $35^{\circ} \mathrm{C}$ and $\mathrm{pH} 5.0$ was found to be sufficient for the extraction of VFAs in contrast to previous studies that have used a lower pH (Aydin et al., 2018). The addition of electrodialysis would remove the VFAs from the PTFE CONC and therefore maintain the concentration gradient across the PTFE membranes, allowing continuous extraction.

\subsection{Addition of electrodialysis to maintain a concentration gradient across the PTFE membrane stack}

The results showed that the concentration in ED CONC increased steadily over $4 \mathrm{~h}$ and did not plateau as in previous experiments without the addition of electrodialysis. In total, $948 \mathrm{mgL}^{-1}$ acetic acid (95\%) was recovered in $4 \mathrm{~h}$ as shown in Fig. 3.

The ability of the PTFE/electrodialysis system to extract VFA 


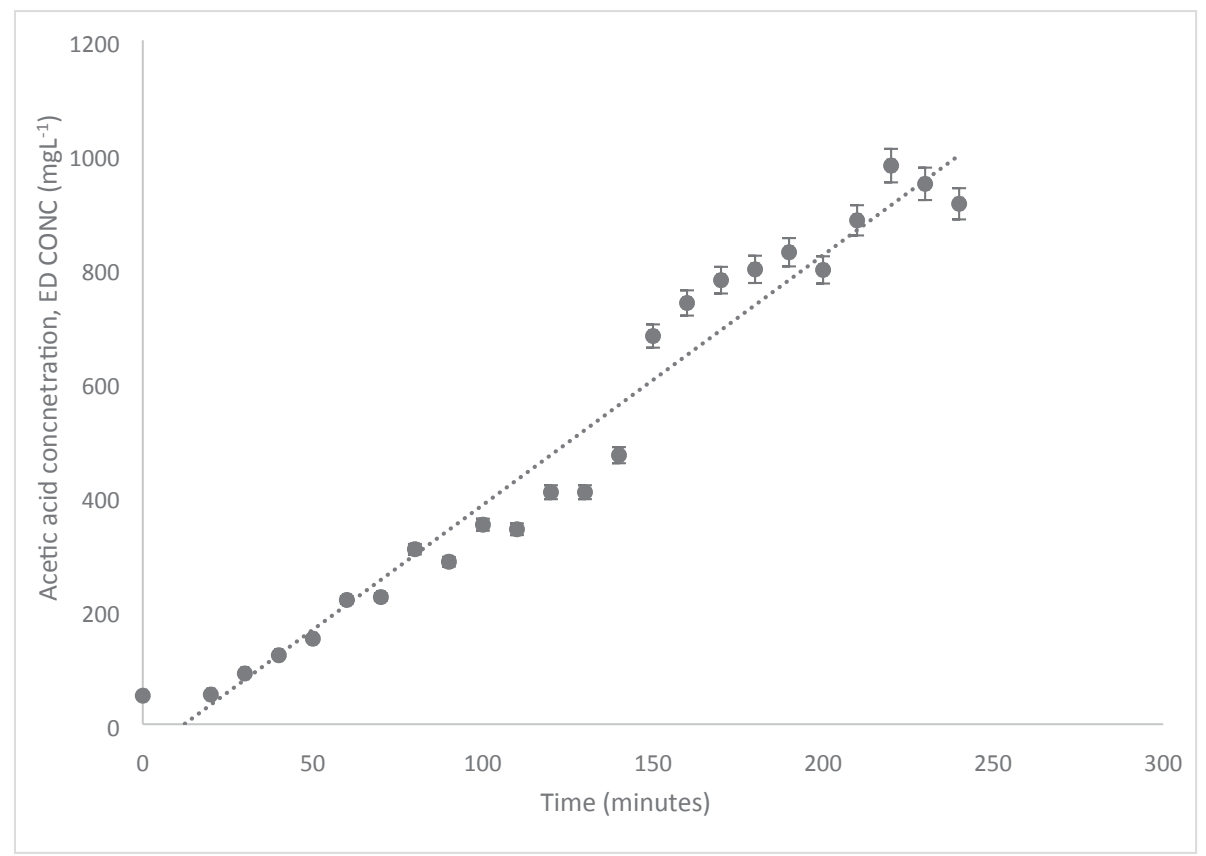

Fig. 3. Extraction of a $1000 \mathrm{mgL}^{-1}$ acetic acid solution using the 5 membrane PTFE configuration and electrodialysis.

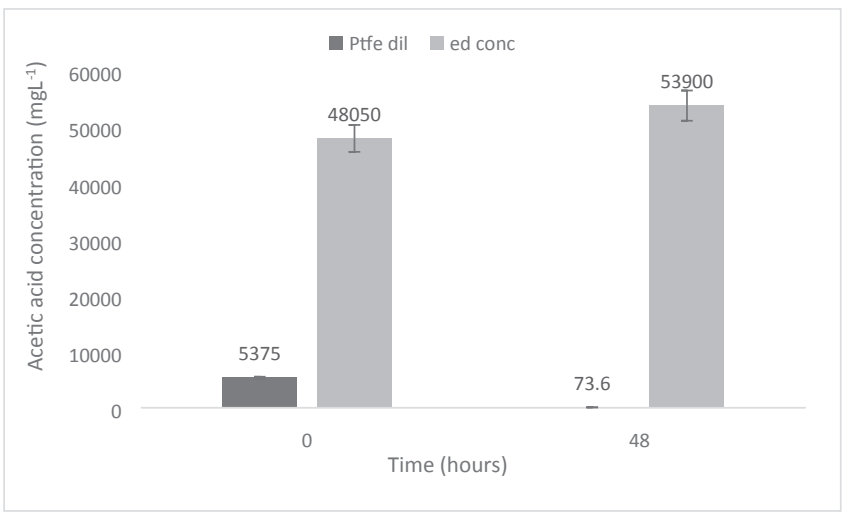

Fig. 4. The difference in VFA concentration in PTFE DIL and ED CONC after $48 \mathrm{~h}$ using the PTFE and electrodialysis system to extract from a reservoir of $5000 \mathrm{mgL}^{-1}$ acetic acid (PTFE DIL) to a reservoir containing $50,000 \mathrm{mgL}^{-1}$ acetic acid (ED CONC).

against the concentration gradient was tested using the 5-membrane configuration and a concentration gradient of $\times 10$ from the PTFE DIL to ED CONC. The results showed that the addition of electrodialysis meant the concentration gradient from high to low could be sustained and $98 \%$ of acetic acid was recovered from PTFE DIL (Fig. 4). This degree of recovery shows great promise for the application of the PTFE/ electrodialysis system to industrial scale biofermenters for the recovery and concentration of VFAs for use as chemical feedstocks. It has previously been demonstrated there is potential for maintaining a continually low reactor VFA concentration to maintain production levels of acids (Nam et al., 2016).

\subsection{Extraction of a mixed VFA solution}

The experiment was repeated with a $5000 \mathrm{mgL}^{-1}$ VFA stock mixture containing $1000 \mathrm{mgL}^{-1}$ each of acetic acid, propionic acid, i-butyric acid, n-butyric acid and valeric acid. These results confirmed that the PTFE membranes are not selective to one VFA but extract all simultaneously, as has been previously demonstrated (Aydin et al., 2018). A total VFA concentration of $2021 \mathrm{mgL}^{-1}$ was recovered in $4 \mathrm{~h}$.
Of this $18 \%$ was acetic acid, $19 \%$ propionic acid, $25 \%$ i-butyric acid, $20 \%$ n-butyric acid and 18\% valeric acid. The extraction selectivity towards particular acid species of the PTFE membranes could be increased using membrane coatings (Aydin et al., 2018). Although this was not explored here it could be a viable solution to the selective separation of mixed fermentation media products and would be a worthwhile area of study for further investigation due to the value of pure VFA feedstock streams for industrial application.

\subsection{Retention of nutrients by the PTFE membrane}

The combination of a PTFE membrane stack and electrodialysis was hypothesised to reduce or even prevent the loss of essential nutrients from fermentation media from a bioreactor and therefore enable extraction of VFAs without compromising the reactor conditions. Table 1 shows the ion chromatography results for the nutrient experiment.

In the experiments, ammonium was not observed to cross the PTFE membrane at all with the level of ammonium found to be below the ion chromatography detection limit in the PTFE CONC. This is likely due to

Table 1

Ion chromatography nutrient analysis results for PTFE DIL, PTFE CONC and ED CONC at the start of the experiment $\left(\mathrm{t}_{0}\right)$ and after $24 \mathrm{~h}\left(\mathrm{t}_{24}\right)$, in $\mathrm{mgL}^{-1}$. Samples analysed in triplicate; average values shown.

\begin{tabular}{|c|c|c|c|c|c|c|}
\hline Ions & $\begin{array}{l}\text { PTFE } \\
\text { DIL } t_{0}\end{array}$ & $\begin{array}{l}\text { PTFE } \\
\text { DIL } t_{24}\end{array}$ & $\begin{array}{l}\text { PTFE } \\
\text { CONC } t_{0}\end{array}$ & $\begin{array}{l}\text { PTFE } \\
\text { CONC } \\
t_{24}\end{array}$ & $\begin{array}{l}\text { ED } \\
\text { CONC } t_{0}\end{array}$ & $\begin{array}{l}\text { ED } \\
\text { CONC } \\
\mathrm{t}_{24}\end{array}$ \\
\hline Calcium & 2.3 & 0.8 & 0.9 & 1.3 & 0.9 & 1.2 \\
\hline Fluoride & 0.5 & 0.1 & 0.2 & 0.2 & 0.1 & 0.3 \\
\hline Magnesium & 0.1 & 0.1 & 0.1 & 0.1 & 0.4 & 0.3 \\
\hline Potassium & 113.0 & 159.7 & 0.1 & 0.1 & 0.1 & 0.6 \\
\hline Sodium & 255.0 & 317.0 & 5.3 & 1.3 & 3.2 & 220.0 \\
\hline Chloride & 631.5 & 663.7 & 3.1 & 0.5 & 2.3 & 224.0 \\
\hline Bromide & 0.1 & 0.2 & 0.1 & 0.1 & 0.1 & 0.1 \\
\hline Nitrate $\left(\mathrm{NO}_{3}\right)$ & 642.0 & 643.5 & 0.3 & 0.1 & 0.5 & 41.7 \\
\hline Nitrite $\left(\mathrm{NO}_{2}\right)$ & 0.1 & 1.4 & 0.1 & 0.1 & 0.1 & 1.9 \\
\hline Sulphate $\left(\mathrm{SO}_{4}\right)$ & 1.6 & 2.3 & 0.5 & 0.3 & 0.5 & 12.3 \\
\hline $\begin{array}{l}\text { Phosphate } \\
\qquad\left(\mathrm{PO}_{4}\right)\end{array}$ & 286.0 & 312.3 & 0.2 & 0.2 & 0.3 & 14.0 \\
\hline $\begin{array}{c}\text { Ammonium } \\
\qquad\left(\mathrm{NH}_{4}\right)\end{array}$ & 212.0 & 264.0 & 0.1 & 0.1 & 0.4 & 3.7 \\
\hline
\end{tabular}




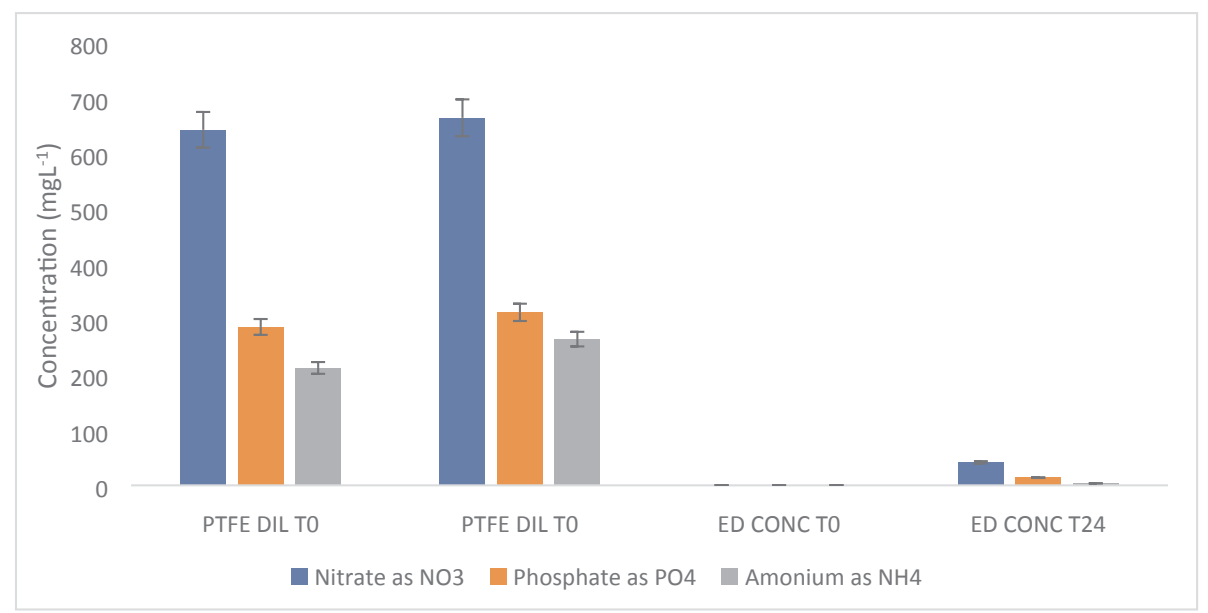

Fig. 5. Ion chromatography analysis of nutrients in the PTFE DIL and ED CONC at $t_{0}$ and $t_{24}$ hours.

the $\mathrm{pH}$ of the solution ensuring that the ammonium ions remain protonated in solution and are therefore not volatile so do not cross the PTFE membrane. In typical microbial fermentations and anaerobic digesters the $\mathrm{pH}$ will usually be maintained between 6 and 8 (Metcalf \& Eddy Inc, Tchobanoglous and Burton, 1991), thus ensuring ammonia contamination of the VFA product would not occur in these types of microbial fermentation downstream processing. Phosphates and nitrates were also not observed to cross suggesting that essential nutrients would remain in the diluate side, therefore maintaining reactor conditions and enabling further bacterial growth and VFA production (Fig. 5).

\subsection{Extraction of acetic acid from synthetic fermentation media}

A synthetic fermentation media was manufactured to test whether the PTFE/electrodialysis system could be applied to a mesophilic anaerobic bioreactor, and potentially other types of microbial fermentation, for the removal of accumulated VFAs. It has previously been reported that biofilms can form on membranes (Zhang et al., 2016). The synthetic reactor contents were filtered through a $0.1 \mu \mathrm{m}$ crossflow filter to eliminate bacteria. The crossflow filter could be implemented in front of the PTFE/electrodialysis system to eliminate bacterial fouling, although high solids systems could cause filter blockage. Biofilms can also grow in bioreactors producing extracellular polymeric substances (EPS) such as exopolysaccharides. EPS have been reported to foul microfiltration units (Morineau-Thomas et al., 2002) and could possibly have an impact on the PTFE membranes, although their effects were not studied here.

Fig. 6 shows the recovery of acetic acid from the synthetic reactor media over $4 \mathrm{~h}$. The results indicate that the PTFE/electrodialysis system would be able to extract VFAs from filtered effluent without the co-extraction of non-volatile ions and nutrient compounds. Any EPS present in the anaerobic digester sludge used to prepare the synthetic reactor contents would be able to cross the crossflow filter and therefore encounter the PTFE membranes. It is possible here that the concentrations of EPS present were so low as to not affect the PTFE membranes. Further work is required to determine whether they would have an impact on the continuous extraction of VFAs from bioreactor systems.

These results have two important consequences; some fermentation procedures operating on nutrient poor substrates, such as $\mathrm{C} 1$ gases and hydrogen benefit from nutrient retention in the fermentation media, enabling nutrient recycling back to the bioreactor. Digesters fed on high solid substrates ( $>5 \%$ TS) would not necessarily benefit from nutrient recycling, although the application of the PTFE/electrodialysis system would lead to a purer VFA product. This could also allow collection of nutrients and VFAs as two separate product streams.

Silicone antifoam is a common additive found in fermentation processes (Delvigne and Lecomte, 2010) and has previously been observed to cause membrane fouling in membrane systems (Lecomte and Dow Corning Corporation, 2012). Silicone antifoam was added to the PTFE DIL chamber to determine its effect on the PTFE membranes. The first titration at $1 \mathrm{~h}$ showed that no acetic acid had crossed the PTFE membrane stack. The experiment was completed, and VFA analysis confirmed that no acetic acid recovery had taken place. The addition of the silicone antifoam was found to foul the PTFE membranes within an hour which could limit the extent of applications the extraction system could be applied to. The fouled membranes were soaked in $0.01 \mathrm{M}$ sodium hydroxide solution for $12 \mathrm{~h}$, washed and left to dry in an incubator overnight at $30{ }^{\circ} \mathrm{C}$ and retested. Their ability to extract a $1000 \mathrm{mgL}^{-1}$ acetic acid stock solution after soaking treatment was restored to levels as before the fouling, indicating fouled membranes can be successfully rehabilitated.

\section{Conclusions}

Stacking PTFE membranes leads to faster VFA recovery times. The addition of electrodialysis ensures a concentration gradient is maintained allowing continuous extraction from a reservoir of $5000 \mathrm{mgL}^{-1}$ to a reservoir of $50,000 \mathrm{mgL}^{-1}$. Essential nutrients are retained on the diluate side, providing a system that can extract VFAs without adversely affecting the nutrient balance during fermentation. This system would be of benefit to fermenters operating on nutrient poor substrates as well as digesters fed on high-solid substrates, possibly enabling separate VFA and nutrient product streams to support the demand for sustainable fuels and feedstocks.

\section{CRediT authorship contribution statement}

Rhiannon Chalmers Brown: Formal analysis, Data curation, Methodology, Investigation, Validation, Writing - original draft, Writing - review \& editing. Romain Tuffou: Formal analysis, Data curation, Methodology, Investigation, Validation, Writing - review \& editing. Jaime Massanet Nicolau: Conceptualization, Funding acquisition, Methodology, Resources, Supervision, Writing - review \& editing. Richard Dinsdale: Conceptualization, Funding acquisition, Project administration, Resources, Validation, Writing - review \& editing, Supervision. Alan Guwy: Conceptualization, Funding acquisition, Project administration, Resources, Validation, Writing - review \& editing, Supervision. 


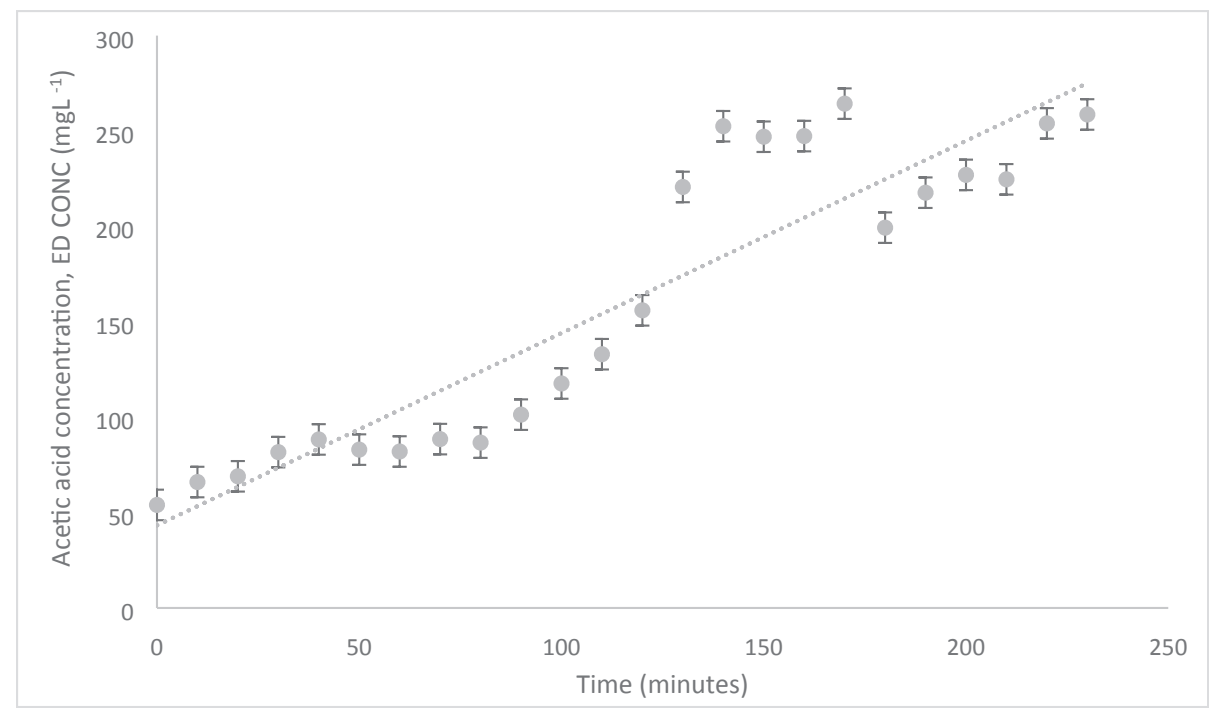

Fig. 6. extraction of acetic acid using a 3-membrane PTFE stack and electrodialysis from a synthetic fermentation media.

\section{Declaration of Competing Interest}

The authors declare that they have no known competing financial interests or personal relationships that could have appeared to influence the work reported in this paper.

\section{Acknowledgements}

This work was joint supported through an ESF KESSII scholarship (Award number MAXI 29439), the ERDF FLEXIS Project (Grant number C80835) and EU Horizon 2020 Res Urbis project (Grant Agreement 730349).

\section{References}

Adnan, S., Hoang, M., Wang, H., Xie, Z., 2012. Commercial PTFE membranes for membrane distillation application: Effect of microstructure and support material. Desalination 284, 297-308. https://doi.org/10.1016/j.desal.2011.09.015.

Alkaya, E., Kaptan, S., Ozkan, L., Uludag-Demirer, S., Demirer, G.N., 2009. Recovery of acids from anaerobic acidification broth by liquid-liquid extraction. Chemosphere 77, 1137-1142. https://doi.org/10.1016/j.chemosphere.2009.08.027.

Atasoy, M., Owusu-Agyeman, I., Plaza, E., Cetecioglu, Z., 2018. Bio-based volatile fatty acid production and recovery from waste streams: Current status and future challenges. Bioresour. Technol. 268, 773-786. https://doi.org/10.1016/j.biortech.2018. 07.042 .

Aydin, S., Yesil, H., Tugtas, A.E., 2018. Recovery of mixed volatile fatty acids from anaerobically fermented organic wastes by vapor permeation membrane contactors. Bioresour. Technol. 250, 548-555. https://doi.org/10.1016/j.biortech.2017.11.061.

Cruwys, J.A., Dinsdale, R.M., Hawkes, F.R., Hawkes, D.L., 2002. Development of a static headspace gas chromatographic procedure for the routine analysis of volatile fatty acids in wastewaters. J. Chromatogr. A 945, 195-209. https://doi.org/10.1016/ S0021-9673(01)01514-X.

Daniell, J., Koepke, M., Simpson, S.D., 2012. Commercial biomass syngas fermentation. Energies 5, 5372-5417. https://doi.org/10.3390/en5125372.

Delvigne, F., Lecomte, J., 2010. Foam formation and control in bioreactors. Encycl. Ind. Biotechnol. 1-13. https://doi.org/10.1002/9780470054581.eib326.

Demler, M., Weuster-Botz, D., 2011. Reaction engineering analysis of hydrogenotrophic production of acetic acid by Acetobacterium woodii. Biotechnol. Bioeng. 108, 470-474. https://doi.org/10.1002/bit.22935.

Jones, R., Massanet-Nicolau, J., Mulder, M.J.J., Premier, G., Dinsdale, R., Guwy, A., 2017. Increased biohydrogen yields, volatile fatty acid production and substrate utilisation rates via the electrodialysis of a continually fed sucrose fermenter. Bioresour. Technol. 229, 46-52. https://doi.org/10.1016/j.biortech.2017.01.015.

Jones, R.J., Massanet-Nicolau, J., Guwy, A., Premier, G.C., Dinsdale, R.M., Reilly, M., 2015. Removal and recovery of inhibitory volatile fatty acids from mixed acid fermentations by conventional electrodialysis. Bioresour. Technol. 189, 279-284. https://doi.org/10.1016/j.biortech.2015.04.001.
Kersten, S.R.A., Ham, Van Der, A.G.J., Schuur, B., Ijmker, H.M., Gramblic, M., 2014. Acetic acid extraction from aqueous solutions using fatty acids. Sep. Purif. Technol. 125, 256-263. https://doi.org/10.1016/j.seppur.2014.01.050.

Kesore, K., Janowski, F., Shaposhnik, V.A., 1997. Highly effective electrodialysis for selective elimination of nitrates from drinking water. J. Memb. Sci. 127, 17-24. https://doi.org/10.1016/S0376-7388(96)00282-7.

Köpke, M., Mihalcea, C., Bromley, J.C., Simpson, S.D., 2011. Fermentative production of ethanol from carbon monoxide. Curr. Opin. Biotechnol. 22, 320-325. https://doi. org/10.1016/j.copbio.2011.01.005.

Lecomte, J., Dow Corning Corporation, 2012. The Effects of Antifoams on Ultrafiltration Membranes.

Lee, H.J., Oh, S.J., Moon, S.H., 2003. Recovery of ammonium sulfate from fermentation waste by electrodialysis. Water Res. 37, 1091-1099. https://doi.org/10.1016/S00431354(02)00451-7.

Massanet-Nicolau, J., Dinsdale, R., Guwy, A., Shipley, G., 2015. Utilising biohydrogen to increase methane production, energy yields and process efficiency via two stage anaerobic digestion of grass. Bioresour. Technol. 189, 379-383. https://doi.org/10. 1016/j.biortech.2015.03.116.

Metcalf \& Eddy Inc, Tchobanoglous, G., Burton, F.L., 1991. Wastewater engineering. Management.

Morineau-Thomas, O., Jaouen, P., Legentilhomme, P., 2002. The role of exopolysaccharides in fouling phenomenon during ultrafiltration of microalgae (Chlorella sp. and Porphyridium purpureum): Advantage of a swirling decaying flow. Bioprocess Biosyst. Eng. 25, 35-42. https://doi.org/10.1007/s00449-001-0278-1.

Nam, C.W., Jung, K.A., Park, J.M., 2016. Biological carbon monoxide conversion to acetate production by mixed culture. Bioresour. Technol. 211, 478-485. https://doi. org /10.1016/j.biortech.2016.03.100.

Oh, S., Logan, B.E., 2003. The relative effectiveness of $\mathrm{pH}$ control and heat treatment for enhancing biohydrogen gas. Production 37, 5186-5190.

Poulin, J.F., Amiot, J., Bazinet, L., 2007. Improved peptide fractionation by electrodialysis with ultrafiltration membrane: Influence of ultrafiltration membrane stacking and electrical field strength. J. Memb. Sci. 299, 83-90. https://doi.org/10. 1016/j.memsci.2007.04.024.

Reyhanitash, E., Kersten, S.R.A., Schuur, B., 2017. Recovery of volatile fatty acids from fermented wastewater by adsorption. ACS Sustain. Chem. Eng. 5, 9176-9184. https://doi.org/10.1021/acssuschemeng.7b02095.

Wang, X., Wang, Y., Zhang, X., Feng, H., Li, C., Xu, T., 2013. Phosphate recovery from excess sludge by conventional electrodialysis (CED) and electrodialysis with bipolar membranes (EDBM). Ind. Eng. Chem. Res. 52, 15896-15904. https://doi.org/10. 1021/ie4014088.

Weier, A.J., Glatz, B.A., Glatz, C.E., 1992. recovery of propionic and acetic acids from fermentation broth by electrodialysis. Biotechnol. Prog. 8, 479-485. https://doi.org/ $10.1021 / \mathrm{bp} 00018 \mathrm{a} 002$.

Yu, H., Zheng, X., Hu, Z., Gu, G., 1998. High-rate anaerobic hydrolysis and acidogenesis of sewage sludge in a modified upflow reactor 69-75.

Zacharof, M.P., Lovitt, R.W., 2014. Recovery of volatile fatty acids (VFA) from complex waste effluents using membranes. Water Sci. Technol. 69, 495-503. https://doi.org/ 10.2166/wst.2013.717.

Zhang, R., Liu, Y., He, M., Su, Y., Zhao, X., Elimelech, M., Jiang, Z., 2016. Antifouling membranes for sustainable water purification: Strategies and mechanisms. Chem. Soc. Rev. 45, 5888-5924. https://doi.org/10.1039/c5cs00579e. 